\title{
STUDIES OF BOTRYTIS CINEREA CAUSING BOTRYTIS GRAY MOLD DISEASE IN CHICKPEA (CICER ARIETINUM L.)
}

\author{
A U Ahmed ${ }^{1}$, S Zaman², M A Mazid², M M Rahman²,M M R Sarkar4, L Arbia², \\ M M Ud-deen ${ }^{3}$, G Kabir ${ }^{4 *}$ \\ 1Institute of Biological Sciences, 2Department of Genetic Engineering \& Biotechnology, ${ }^{3}$ Department of Crop \\ Science \& Technology University of Rajshahi, ${ }^{4}$ Prof. S. Alam Cytogenetics Laboratory, Department of Botany \\ University of Rajshahi, Rajshahi-6205, Bangladesh
}

\begin{abstract}
Context: To investigate the morphological and pathological information on causal organism Botrytis cinerea for better understanding of the infection process and controlling outbreaks of the most damaging disease, Botrytis Gray Mold (BGM), of chickpea.

Objectives: To study the cultural and morphological characteristics and growth requirements of Botrytis cinerea Pers. ex. Fr. This study was also aimed to know about the cytological and genetic behavior of $B$. cinerea in relation to its pathogenicity and the infection process on chickpea.

Materials and Methods: A total of 83 isolates of Botrytis cinerea Pers. ex. Fr. collected from the major chickpea growing areas of Bangladesh were studied under 5 and 2 different groups based on their cultural and morphological characteristics, respectively. Four different types of isolates were observed and characterized considering the arrangement of sclerotia by growing them on PDA. Cultural characteristics such as colony color, shape, margin and texture of $B$. cinerea isolates were observed on the prepared PDA medium. Morphological characteristics in terms of sclerotia color, shape and size, ability of sclerotia production and their arrangement were observed on PDA medium after three days of incubation at $20^{\circ} \mathrm{C}$. The prepared samples were placed in a platinum coater providing $10 \mathrm{~mA}$ current flow and then placed into the Scanning Electron Microscope (SEM) for obtaining the image. The conidial observation was taken using aqua suspension under the fluorescence microscope at 19V/100W. SEM observation was made to study the infection process of $B$. cinerea. Data on quantitative and qualitative cultural characteristics were put into analytical software 'SPSS 11.5 for Windows' and nonhierarchical clustering was performed.

Results: The mean sizes of five isolates of $B$. cinerea were 8.02-12.3x 5.1-9.0 $\mu \mathrm{m}$ (volume 158.12-445.38 $\mu \mathrm{m}^{3}$ ). The pathogen $B$. cinerea grew well on malt-extract agar (MEA) and chickpea dextrose agar (CDA) medium. The highest $(81.26 \mathrm{~mm})$ average mycelial radial growth was obtained on MEA followed by CDA (81.11 mm). Maximum disease in the shortest incubation period was produced with the inoculum concentration of $2.5 \times 10^{4}$. More pathogenicity and higher disease score was performed by the isolates containing higher mean number of nucleus per conidia than the isolates containing lower values. Optimum temperature and incubation time for conidial germination was observed at $20^{\circ} \mathrm{C}$ and $24 \mathrm{~h}$, respectively. More than $90 \%$ relative humidity was needed for the germination of $B$. cinerea conidia. $B$. cinerea survived in all plant parts up to next cropping season. Sclerotia of $B$. cinerea were also found to survive in the soil up to 9 months. All the 5 isolates of $B$. cinerea remained viable after 3 years of storage in sterile water at $-80^{\circ} \mathrm{C}$ and in sand at $4^{\circ} \mathrm{C}$ with same pathogenicity.

Conclusion:The cyto-pathological observations including cultural and morphological information of the causal pathogen $B$. cinerea might be useful in controlling the outbreaks of the disease BGM and ultimately reducing the yield loss of the valuable crop chickpea.
\end{abstract}

Key words: Botrytis cinerea, Sclerotia, Chickpea, Botrytis Gray Mold, BGM. Introduction

Chickpea (Cicer arietinum L.) is the third most important legume crop in the world and is grown in at least 44 countries of the world (Bakr et al. 2002). It is a valued source of protein ranges from 25.3 to 28.9\% (Hulse, 1991). Globally, chickpea is cultivated on about 11.12 million ha, adding 8.62 million tonnes of grain to the global food basket (FAO 2005). The climate and agro-ecological conditions of Bangladesh favours the rapid development and growth of various plant pathogens (Ahmed 1996). Susceptibility of chickpea to a number of fungal pathogens from seedling stage to maturity is the primary cause of its low yield. So far, 17 diseases of

*Corresponding author's E-mail: gkabir@ru.ac.bd 
chickpea are recorded in Bangladesh (Bakr and Rashid 2007). Among the diseases, Botrytis Gray Mold (BGM) caused by B. cinerea Pers. ex. Fr., is the most damaging disease of chickpea (Pande et al. 2006), first reported from India by Shaw and Ajrekar in 1915. Globally, the disease has threatened the chickpea crop so much that the cultivation area of the crop has come down to 7,224 ha from more than $10,00,000$ ha within a span of 20 years (FAO 2012).

The disease was first documented in Bangladesh during 1981 and claimed to be the production constrains in 1988, destroying almost all parts of chickpea crop (Bakr and Ahmed 1992). Currently, it is considered the most damaging foliar disease of chickpea in Bangladesh (Bakr et al. 2005). B. cinerea attacks all aerial parts of the plant, with growing tips and flowers being the most vulnerable (Pande et al. 2002). Symptoms of gray mold can be spread mostly through spores in stems, pods, flowers and in mature seeds of this crop (Bakr et al. 2002).

It is very important to know the biology of a causal organism for management of the disease. A detail study on $B$. cinerea is therefore needed due to the following facts: i) frequent disease outbreaks, ii) susceptibility of genotype at different locations, iii) genotypic and phenotypic variability, and iv) adaptability to diverse environments. Keeping all these views in mind the present study was undertaken to isolate $B$. cinerea from the major chickpea growing areas of Bangladesh. This study was also aimed to investigate the infection process of $B$. cinerea on chickpea.

\section{Materials and Methods}

The $B$. cinerea Pers. ex. Fr. were isolated from different major chickpea growing areas of Bangladesh. All the experiments were conducted during July 2007 to October 2011 in the pot house and research field of Plant Pathology Laboratory, Bangladesh Agricultural Research Institute (BARI), Joydebpur, Gazipur, Bangladesh.

The pathogens were isolated using standard culture techniques (Davidson et al. 2007). The fungal cultures were studied under stereoscopic and compound microscope for identification of the desired pathogens. After identification $B$. cinerea was purified following single spore isolation technique and the stock culture of the isolates was kept on extra pure dehydrated PDA medium ( $\mathrm{pH} \mathrm{5.0)}$ in test tubes slant at $4 \pm 0.5^{\circ} \mathrm{C}$ in a refrigerator for further use. Cultural characteristics such as colony color, shape, margin and texture of $B$. cinerea isolates were observed on Potato Dextrose Agar (PDA) medium. Morphological characteristics in terms of sclerotia color, shape and size, ability of sclerotia production and their arrangement were observed after three days of incubation at $20^{\circ} \mathrm{C}$ on PDA medium. Samples were post-fixed in $1 \%$ osmium tetroxide in $0.1 \mathrm{M}$ cacodylate buffer for $1 \mathrm{~h}$ and critical point drying was made by liquid $\mathrm{CO}_{2}$. The prepared samples were next placed in a platinum coater providing $10 \mathrm{~mA}$ current flow and then into the Scanning Electron Microscope (SEM) for obtaining the image. The conidial observation was taken using aqua suspension under the fluorescence microscope at 19V/100W. Observation on the symptoms of BGM disease susceptible variety 'Nobin' was made under natural infection condition throughout the cropping season of three consecutive years as control. To study the infection process of $B$. cinerea, five fresh leaves of chickpea were placed on a plate and a conidial suspension $\left(2.5 \times 10^{4} \mathrm{ml}^{-1}\right)$ of 7 day old sporulated culture of $B$. cinerea was sprayed on the adaxial and abaxial surface of the leaves. A piece of wet cotton was used to maintain $100 \%$ humidity inside the plate. The plate was sealed with parafilm and incubated at $20{ }^{\circ} \mathrm{C}$ for $24 \mathrm{~h}$. The leaves were then prepared for SEM observation. For grouping of $B$. cinerea isolates, data on quantitative and qualitative cultural characteristics were put into analytical software 'SPSS 11.5 for Windows' and nonhierarchical clustering was performed. Single spore isolation of $B$. cinerea were grown on PDA medium and were incubated for 7 days at $20^{\circ} \mathrm{C}$ with $12 \mathrm{~h}$ light and dark period, alternatively. Conidia thus formed were collected, 
concentrated to $1 \times 10^{8}$ spores $\mathrm{ml}^{-1}$ in distilled water and were stored in a deep freezer at $-80^{\circ} \mathrm{C}$ for long term preservation. The volumes of conidia were calculated using a formula described by Shirane (1989) as follows: Conidial volume $\left(\mu \mathrm{m}^{3}\right)=\mathrm{L} \times \mathrm{W}^{2} \times \pi / 6$, where, $\mathrm{L}=$ Conidial length $(\mu \mathrm{m})$ and $\mathrm{W}=$ Conidial width $(\mu \mathrm{m})$.

Mycelial growth of five isolates of $B$. cinerea was evaluated on six media such as PDA, CDA (Czapek Dox Agar), OMA (Oat Meal Agar), MEA (Malt Extract Agar), LDA (Lysine Decarboxylase Agar), V8A (V8 Juice Agar) and were inoculated by placing a $5 \mathrm{~mm}$ growing mycelia of each isolate and placed in an incubator at $20^{\circ} \mathrm{C}$ under $12 \mathrm{~h}$ photoperiod. Effect of temperature on mycelial growth was evaluated on PDA at 5, 10, 15, $20,25,30$ and $35{ }^{\circ} \mathrm{C}$ in the dark. Colony diameters were measured at 7 days after inoculation. To examine the effect of $\mathrm{pH}$ on colony growth, fungus was inoculated on PDA with $\mathrm{pH} 6.0$, and 6.5, respectively and incubated at $20^{\circ} \mathrm{C}$ for 3 additional days to determine whether the fungus growth resumed or not. Radial growth was recorded on each day.

The IC (inoculum concentration) effect was investigated on 15 day-old chickpea plants of 'Nobin' and 'ICCL 87322 ' were collected from BARI. Plants were inoculated by spraying to runoff with spore suspensions containing $5 \times 10^{2}, 1 \times 10^{3}, 1 \times 10^{4}, 2.5 \times 10^{4}$, and $5 \times 10^{5}$ spores $/ \mathrm{ml}$. Control plants were sprayed with sterile distilled water. Suspensions were applied with a spray atomizer with an adjustable nozzle to form a high density of fine droplets on the aerial parts of the plants. Immediately after inoculation, the plants were covered for 48h with transparent polyethylene bags with distilled water sprayed inside. After IP (Inoculum Penetration), the plants were uncovered and kept in a glasshouse at $25^{\circ} \mathrm{C}$ temperature. The isolate which had more conidia could contain higher number of nucleus, so it could show more aggressiveness than the others and could spread the disease so fast among the seedlings.

Growing mycelium of five $B$. cinerea isolates viz. $B c c 3, B c c 17, B c c 50, B c c 78$ and $B c c 81$ were transferred to PDA slants and stored at $4{ }^{\circ} \mathrm{C}$ for long term preservation. Spores cultured on chickpea whole grain of each isolate were stored in silica gel, soil and sand at $4^{\circ} \mathrm{C}$. Some portions of conidiophores were stored in water at $-80^{\circ} \mathrm{C}$. Aggressiveness of each isolate of $B$. cinerea was examined by test of their pathogenicity on chickpea. The plants were inoculated by all the isolates of $B$. cinerea after storage. Disease scoring was done following same scoring scale as used earlier.

\section{Results}

Symptoms of BGM disease were observed first by flowers dropping (Plate 1A). Infected flower was rotted later on (Plate 1B). Dark brown circular lesions were developed on leaflets (Plate 1C). Erect hairy sporophore with spore mass was developed on almost all infected parts of chickpea plant especially on flowers and pods (Plate 1D). The mycelium of $B$. cinerea consists of a set of filaments or hyphae loculated, cylindrical and thin, septate and hyaline to brown in colour (Plate 2). Conidiophores of $B$. cinerea consist of more or less straight twisted type microfilament, which branches alternately to a greater extent in the apical region (Plate 3). At the terminal end of these branches, globose swellings or vesicles were formed, where conidia arose in cluster form (Plate 4). Macro conidia of $B$. cinerea were hyaline or pale brown in colour, single celled, oval, globose or short cylindrical (Plate 5A) and microconidia were smaller in size (Plate 5B). Single or multinucleate macro conidia were observed in all the isolates of $B$. cinerea (Plate $5 C$ ).

The issuance of conidia started at the terminal conidiophores and spread rapidly to the side branches (Plate 6). When the conidia production was finished, the portion of the bore conidiophores dried, it shrunk and dried up (Plate 7). Different isolates produced black coloured sclerotia in different patterns on PDA media (Plate 8). Under controlled condition and after $24 \mathrm{~h}$ of incubation, $B$. cinerea was found to penetrate through stomata of chickpea leaf (Plate 9). The mycelial growth was extended throughout the leaf surface and produced mycelial 
mat even after 24h of incubation (Plate 10). The collected 83 isolates were grouped in five on PDA medium (Fig. 1) where the highest (34) number of isolates were in group V and then 16 isolates were in group III. Twelve isolates were in group I and IV. Group II contained the lowest (9) number of isolates.

The mycelial growth of all five isolates increased as temperature and $\mathrm{pH}$ was increased up to $200^{\circ} \mathrm{C}$ and 4.5 , respectively and then decreased rapidly with further increase of temperature and pH increased (Fig. 2 \& Fig 3).Germination of conidia of $B$. cinerea increased with the increase of relative humidity.
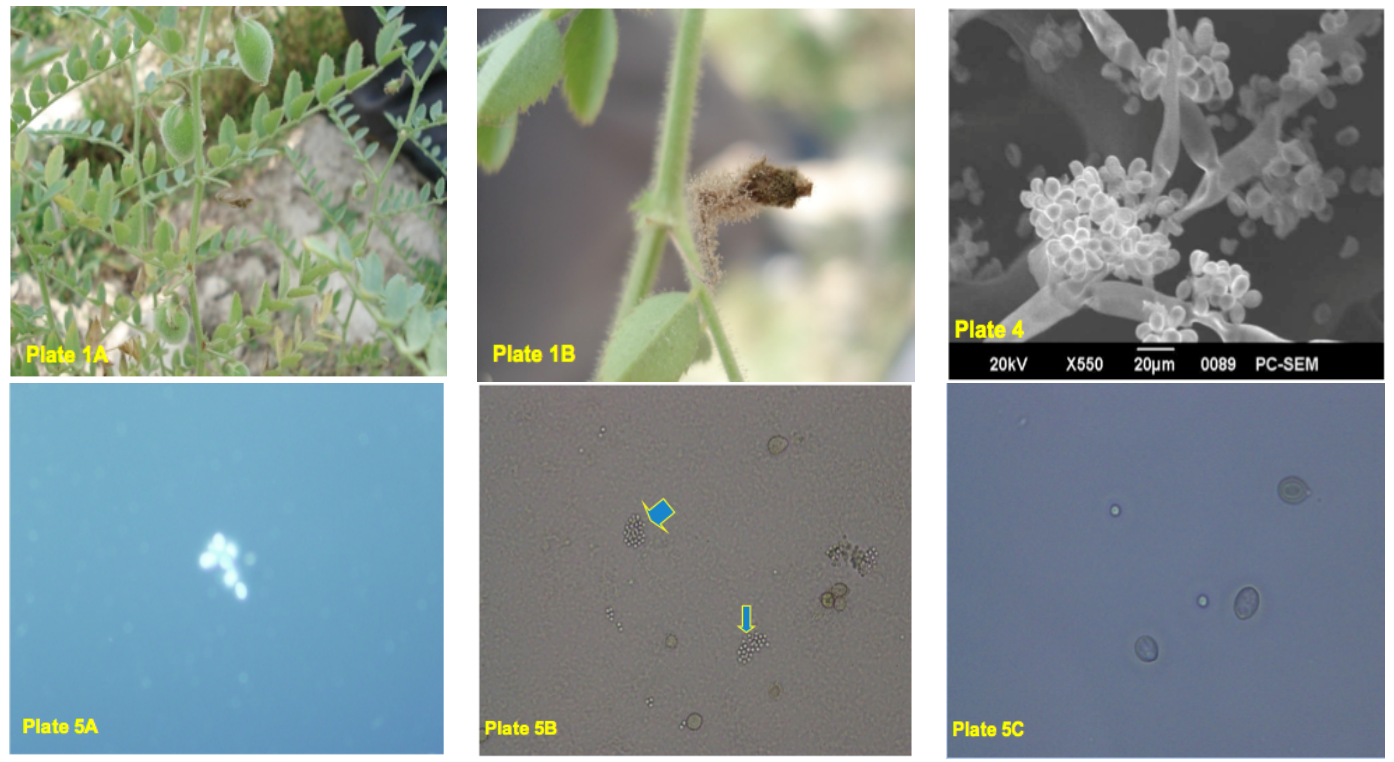

Plate 1.Botrytis gray mold disease symptom in chickpea. A: flower attacked by B. cinerea, B: sporulation on rotting flower, C: lesion on leaf and D: pod covered by sporophores. Plate 2.Mycelium of Botrytis cinerea seen under microscope at 400x.Plate 3. Dichotomously branched conidiophores of $B$. cinerea.
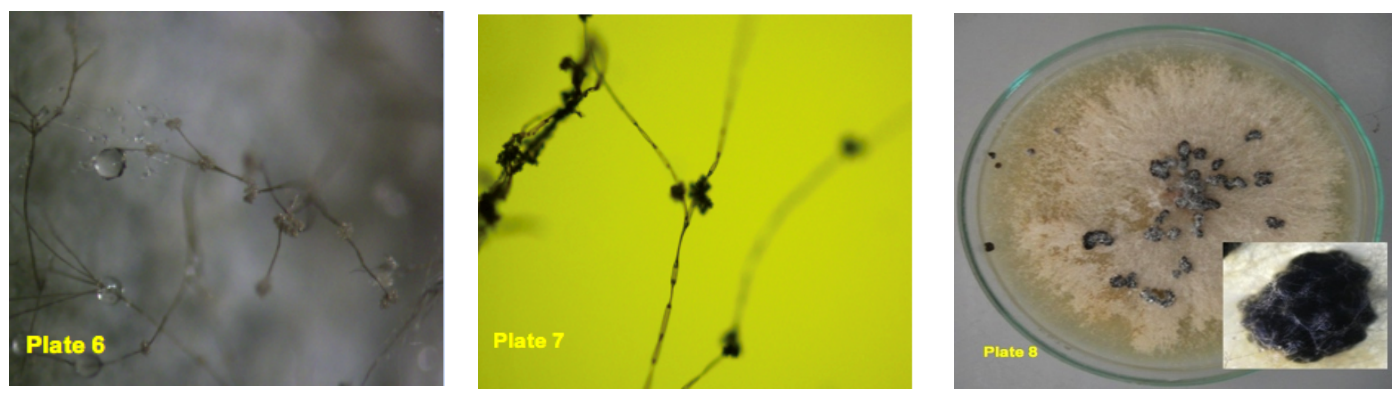

Plate 4. Scanning Electron Microscopic image of conidial cluster of $B$. cinerea borne on conidiophore. Plate 5. Conidia of $B$. cinerea.A: macro conidia seen under fluorescent microscope, $B$ : micro conidia seen under compound microscope, C: single or multinucleate conidia seen under compound microscope. Plate 6.Sporulation of Botrytis cinerea at the terminal end of conidiophores.Plate 7. Drying and shrinking of conidiophores of $B$. cinerea after sporulation. Plate 8. Sclerotia of $B$. cinerea formed on PDA medium. 

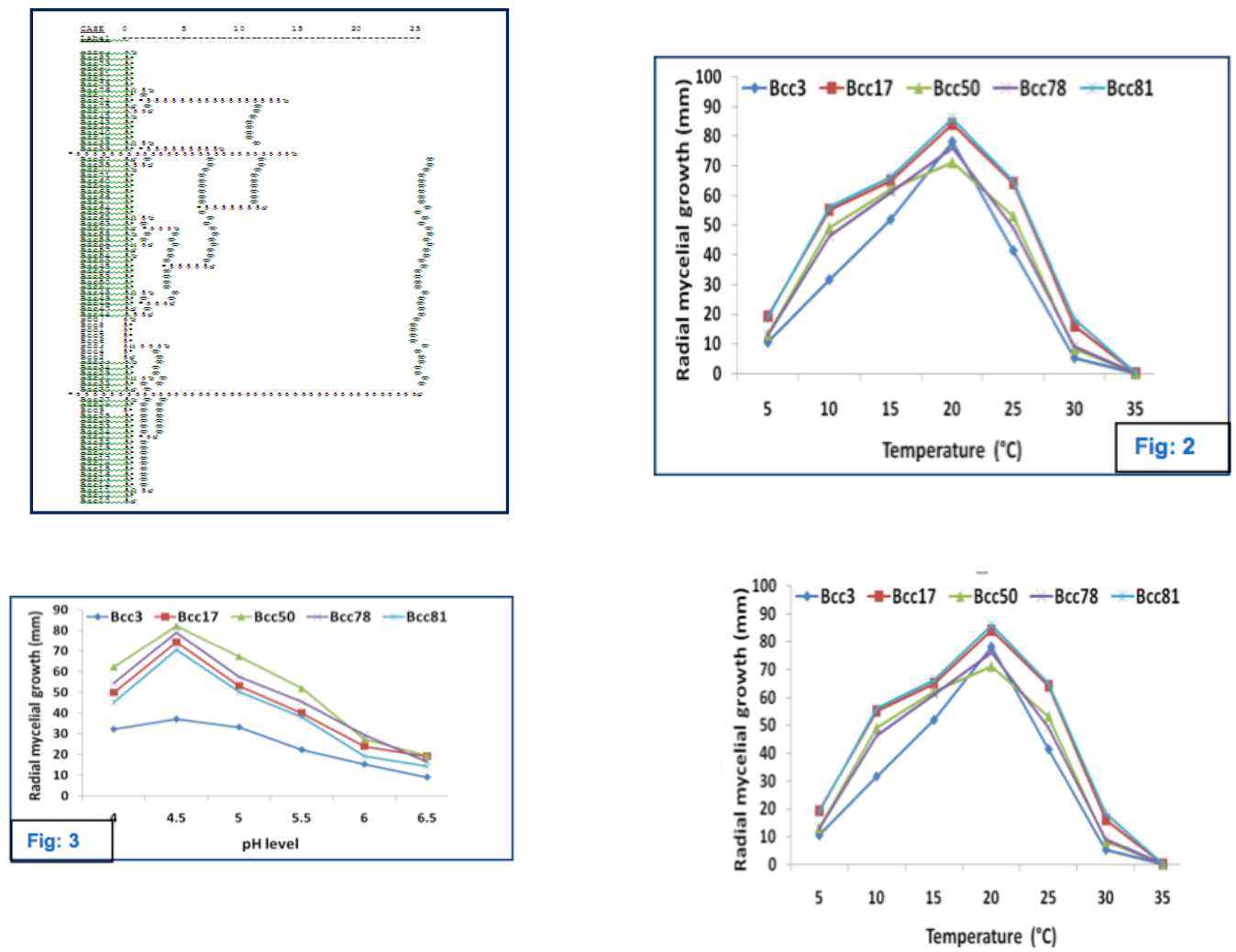

Fig. 1. Dendrogram showing grouping of $83 B$. cinerea isolates based on their cultural morphology on PDA. Fig. 2. Effect of temperature on radial mycelial growth of $B$. cinerea isolates.Fig. 3. Effect of pH on radial mycelial growth of $B$. cinerea isolates. Fig. 4. Effect of relative humidity on conidial germination of $B$. cinerea incubated for $24 \mathrm{~h}$.

Conidial germination of $B$. cinerea isolates after $24 \mathrm{~h}$ of incubation on glass slides occurred within the range of 75 to $100 \%$ relative humidity (RH) (Fig. 4). Aggressiveness of B. cinerea isolates were significantly influenced by number of nucleus per conidia (Table 1). Highest disease score (9.0) was performed by the isolate Bcc81 with highest (5.3) mean number of nucleus per conidia (Table 1).

Table 1. Aggressiveness of $B$. cinerea isolates as influenced by number of nucleus per conidia.

\begin{tabular}{|c|c|c|}
\hline Isolates & Mean nuclear number & $\begin{array}{c}\text { Aggressiveness (Disease rating) } \\
\text { (1-9 Scale) }\end{array}$ \\
\hline Bcc3 & 3.6 & $5.2 \mathrm{c}$ \\
\hline Bcc17 & 4.1 & $6.4 \mathrm{~b}$ \\
\hline Bcc50 & 4.4 & $7.0 \mathrm{~b}$ \\
\hline Bcc78 & 4.9 & $8.8 \mathrm{a}$ \\
\hline Bcc81 & 5.3 & $9.0 \mathrm{a}$ \\
\hline
\end{tabular}

The highest percentage of germination of $B$. cinerea conidia was occurred at $20^{\circ} \mathrm{C}$ after $24 \mathrm{~h}$ of incubation. Results on conidial germination with respect to change of temperature and incubation period are presented in Table 2. 
Table 2.Effect of temperature and incubation time on conidial germination of $B$. cinerea.

\begin{tabular}{|c|c|c|c|}
\hline Temperature $\left({ }^{\circ} \mathbf{C}\right)$ & Germination (\%) & $\begin{array}{c}\text { Incubation time } \\
\text { (hour) }\end{array}$ & $\begin{array}{c}\text { Germination } \\
\text { (\%) }\end{array}$ \\
\hline 5 & $13.33 \mathrm{~d},(16.40)$ & 2 & $4.83 \mathrm{e},(10.21)$ \\
\hline 10 & $25.93 \mathrm{c},(26.33)$ & 4 & $10.37 \mathrm{~d},(17.96)$ \\
\hline 15 & $38.73 \mathrm{~b},(37.33)$ & 6 & $23.00 \mathrm{c},(27.92)$ \\
\hline 20 & $48.20 \mathrm{a},(45.40)$ & 12 & $54.78 \mathrm{~b},(47.89)$ \\
\hline 25 & $40.46 \mathrm{~b},(38.38)$ & 24 & $66.05 \mathrm{a},(55.42)$ \\
\hline 30 & $24.20 \mathrm{c},(27.46)$ & & \\
\hline
\end{tabular}

Figures in the parenthesis are the arcsine transformed value of original data. Means having the same letter in a column do not differ significantly at $1 \%$ level.

B. cinerea survived in all plant parts, mostly in flower part. Maximum (100\%) survival was observed in all plant parts up to 30 days. All the sclerotia survived the first 30 days and gradually decreased upto 7 months; again it was increased upto 9 months. Viability of all the 5 isolates and aggressiveness were observed after three years of storage using different methods (Table 3 \&Table 4).

Table 3.Viability of $B$. cinerea isolates after 1,2 or 3 years of storage using different methods.

\begin{tabular}{|c|c|c|c|c|c|c|c|c|c|c|c|c|c|c|c|}
\hline \multirow{4}{*}{$\begin{array}{l}\text { Storage } \\
\text { methods }\end{array}$} & \multicolumn{15}{|c|}{ Isolates } \\
\hline & \multicolumn{3}{|c|}{ Bcc3 } & \multicolumn{3}{|c|}{ Bcc17 } & \multicolumn{3}{|c|}{ Bcc50 } & \multicolumn{3}{|c|}{ Bcc78 } & \multicolumn{3}{|c|}{ Bcc81 } \\
\hline & \multicolumn{3}{|c|}{ Year } & \multicolumn{3}{|c|}{ Year } & \multicolumn{3}{|c|}{ Year } & \multicolumn{3}{|c|}{ Year } & \multicolumn{3}{|c|}{ Year } \\
\hline & 1 & 2 & 3 & 1 & 2 & 3 & 1 & 2 & 3 & 1 & 2 & 3 & 1 & 2 & 3 \\
\hline Silica gel & + & + & - & + & + & c & + & + & + & + & + & + & + & + & + \\
\hline Dry & - & - & - & - & - & - & + & - & - & + & + & - & + & + & - \\
\hline Soil & + & + & C & + & + & C & + & + & c & + & + & C & + & + & + \\
\hline Sand & + & + & + & + & + & + & + & + & + & + & + & + & + & + & + \\
\hline Water & + & + & + & + & + & + & + & + & + & + & + & + & + & + & + \\
\hline Glycerin & + & + & C & + & + & c & + & + & c & + & + & C & + & + & C \\
\hline PDA & - & - & - & - & - & - & + & - & - & + & - & - & + & + & c \\
\hline
\end{tabular}

- : no mycelial growth; + : mycelial growth; C : contaminated culture.

Table 4. Aggressiveness of $B$. cinerea isolates after 3 years of storage using different methods.

\begin{tabular}{|c|c|c|c|c|c|c|c|c|c|c|c|c|c|c|c|}
\hline \multirow{4}{*}{$\begin{array}{l}\text { Storage } \\
\text { methods }\end{array}$} & \multicolumn{15}{|c|}{ Isolates } \\
\hline & \multicolumn{3}{|c|}{ Bcc3 } & \multicolumn{3}{|c|}{ Bcc17 } & \multicolumn{3}{|c|}{ Bcc50 } & \multicolumn{3}{|c|}{ Bcc78 } & \multicolumn{3}{|c|}{ Bcc81 } \\
\hline & \multicolumn{3}{|c|}{ Year } & \multicolumn{3}{|c|}{ Year } & \multicolumn{3}{|c|}{ Year } & \multicolumn{3}{|c|}{ Year } & \multicolumn{3}{|c|}{ Year } \\
\hline & 1 & 2 & 3 & 1 & 2 & 3 & 1 & 2 & 3 & 1 & 2 & 3 & 1 & 2 & 3 \\
\hline $\begin{array}{c}\text { Initial } \\
\text { virulence }\end{array}$ & 5.4 & 5.4 & - & 6.3 & 6.3 & - & 7.0 & 6.9 & 6.9 & 8.7 & 8.6 & 8.6 & 9.0 & 9.0 & 9.0 \\
\hline Silica gel & 5.4 & 5.4 & - & 6.3 & 6.3 & - & 7.0 & 6.9 & 6.9 & 8.7 & 8.6 & 8.6 & 9.0 & 9.0 & 9.0 \\
\hline Dry & - & - & - & - & - & - & 6.9 & - & - & 8.6 & 8.6 & - & 9.0 & 9.0 & - \\
\hline Soil & 5.4 & 5.5 & - & 6.4 & 6.4 & - & 7.0 & 6.9 & - & 8.8 & 8.6 & - & 9.0 & 7.0 & 6.0 \\
\hline Sand & 5.5 & 5.5 & 5.4 & 6.5 & 6.5 & 6.5 & 7.0 & 7.0 & 7.0 & 8.8 & 8.7 & 8.7 & 9.0 & 9.0 & 9.0 \\
\hline Water & 5.5 & 5.5 & 5.4 & 6.5 & 6.5 & 6.5 & 7.0 & 7.0 & 7.0 & 8.8 & 8.7 & 8.7 & 9.0 & 9.0 & 9.0 \\
\hline Glycerin & 5.3 & 5.3 & - & 6.4 & 6.4 & - & 7.0 & 7.0 & - & 8.6 & 8.6 & - & 9.0 & 9.0 & - \\
\hline PDA & - & - & - & - & - & - & 6.9 & - & - & 8.6 & - & - & 9.0 & 8.0 & - \\
\hline
\end{tabular}




\section{Discussion}

Conidiophores of $B$. cinerea were arisen from the hyphal mass and twisted type microfilament, which branches alternately. At the terminal end of these branches two types of conidia viz. macro and micro conidia arose in cluster form. Macro conidia of all the isolates were hyaline or pale brown in colour, single celled, oval, globose or short cylindrical and single or multinucleated. The abovementioned characteristics of $B$. cinerea were in conformity with the findings of other researchers (Acero, 2006).

The infection process of $B$. cinerea on chickpea leaves was studied under controlled condition. Most of the spores were found to be germinated on leaf surface within 4-8h after artificial inoculation of spores at higher concentration and incubated at $20{ }^{\circ} \mathrm{C}$ temperature with $100 \%$ relative humidity. This result showed similarity with that of Pandey (1988) who artificially inoculated chickpea by B. cinerea conidia and observed the conidia to be germinated within $6-8 \mathrm{~h}$ on leaf surface. After $24 \mathrm{~h}$ of incubation, $B$. cinerea found to penetrate through stomata of chickpea leaf.

In the present study, all the isolates grew within a wide range of temperature of $5-30{ }^{\circ} \mathrm{C}$. Maximum mycelial growth was observed at $20^{\circ} \mathrm{C}$ and failed to grow at $35^{\circ} \mathrm{C}$. Result of this study is very similar to the findings of Ahmed et al. (2007), Hosen et al. (2010b) and Pande et al. (2010).

The $\mathrm{pH}$ of the medium can be changed during incubation even if the medium is well buffered. Thus, the study of $\mathrm{pH}$ effects on fungal growth is difficult because of the varying $\mathrm{pH}$ which may alter other features of the medium (Ingold and Hudson, 1993). In this study, B. cinerea grew abundantly between pH 4.0 and 6.5 with a maximum growth at $\mathrm{pH}$ 4.5. Similar results were found by Hosen et al. (2010b), who found the highest growth between $\mathrm{pH} 4.5$ and pH 6.5, with definite optima at pH 4.5 for $B$. cinerea.

In this study, relative humidity higher than $94 \%$ was critical for conidial germination of $B$. cinerea. The effects of high relative humidity in combination with specific temperatures on spore germination can be useful elements in predicting the likelihood of disease occurrence under field conditions. Present results obtained on the effect of relative humidity on the germination of conidia in-vitro were similar to the results previously reported in the literature regarding the conditions required by $B$. cinerea for infection in chickpea (Rewal and Grewal, 1989) and other crops (Nair and Allen, 1993; Eden et al. 1996a).

The strains with higher number of nuclei per conidia produced higher degree of infectivity as well as higher disease score. This result is in conformity with the findings of Phillips et al. (1987), who experimented on rose flower and observed the strains of $B$. cinerea with higher number of nuclei per conidia produced higher disease in rose flower.

\section{Conclusion}

CDA and MEA medium were found to be the most favourable for radial growth of mycelium of all tested isolates. Temperature and $\mathrm{pH}$ fluctuations found crucial for the mycelial growth of $B$. cinerea. Aggressiveness and the highest disease score were performed by the isolate with the highest mean number of nucleus per conidia. Conidial germination of $B$. cinerea was highly affected by the incubation temperature and time. Comparison among different storage methods indicates that dry condition can reduce the conidial germination and pathogenicity of $B$. cinerea. So, these cyto-pathological observations of the causal pathogen $B$. cinerea including cultural and morphological information might be useful in controlling the outbreaks of the disease BGM and ultimately aid in reducing the yield losses of the valuable crop chickpea.

\section{References}

Acero FJF. 2006. Application of proteomics to the characterization of mechanisms pathogenicity in Botrytis cinerea: Use and evaluation of new fungicides. Ph.D thesis, The University of Cadiz, Spain.

Ahmed AU, Pande S, Basandrai AK, Kishore GK,Rao JN. 2007. Variation in isolates of Botrytis cinerea causing Botrytis gray mold in chickpea. Bangladesh J. Agril. Res., 32(1):135-143.

Ahmed AU. 1996. Variation in twenty seven isolates of Bipolaris sorokiniana from wheat. MS Thesis, Bangabandhu Sheikh Mujibur Rahman Agricultural University (Former IPSA), Salna, Gazipur, Bangladesh. 
Bakr MA, Rashid MH. 2007. Strategic intervention on pulse disease research at BARI. In: Advances in Plant Pathological Research in Bangladesh. Plant Pathology Division, Bangladesh Agricultural Research Institute, Joydebpur, Gazipur, Bangladesh. 42-57.

Bakr MA, Afzal MA, Johansen C, MacLeod WJ, Siddique KHM. 2005. Integrated management of Botrytis grey mould of chickpea: On-farm evaluation in Bangladesh. In: 'Paper presented in the 15th Australasian Plant Pathology Conference on Innovations for Sustainable Plant Health'. Deakin University Waterfront Campus, Geelong, Vic. 2629 September 2005. pp. 193. (Australian Plant Pathology Society: Canberra).

Bakr MA, Rahman ML, Ahmed AU. 2002. Manifestation of botrytis grey mould in chickpea in Bangladesh. In: Bakr, M. A., Siddique, K. H. M. and Johansen, C. (eds.) Integrated Management of Botrytis Grey Mould of Chickpea in Bangladesh and Australia.Summary Proceedings of a Project Inception Workshop. (pp.63-69) Bangladesh Agricultural Research Institute, Joydebpur, Gazipur, Bangladesh.

Bakr MA, Ahmed F. 1992.Botrytis gray mold of chickpea in Bangladesh.In: 'Botrytis gray mold of chickpea. Summery Proceedings of the BARI/ICRISAT Working Group Meeting' (Eds. Haware, M. P., Faris, D. G. and Gowda, C. L. L.). ICRISAT: Patancheru, AP, India. 10-12.

Davidson JA, Pande S, Bretag TW, Lindbeck KD, Krishna-Kishore G. 2007. Biology and management of Botrytis spp. in legume crops. In Botrytis: biology, pathology and control, 295-318. Springer Netherlands.

Eden MA, Hill RA, Stewart A. 1996a.Biological control of Botrytis stem infection of greenhouse tomatoes.Plant Pathology, 45:276-284. http://dx.doi.org/10.1046/.1365-3059.1996.d01-119.x

FAO. 2005. 'FAO bulletin of statistics.' (Food and Agricultural Organizations of the United Nations, Rome). http://faostat.fao.org/faostat/.

FAO. 2012. 'FAO bulletin of statistics.' (Food and Agricultural Organizations of the United Nations, Rome). http://faostat.fao.org/faostat/.

Hosen MI, Ahmed AU, Islam MR. 2010b. Physiological variability and in vitro antifungal activity against Botrytis cinerea causing botrytis gray mold of chickpea (Cicer arietinum L.).Spain J Agric Res., 8(3):750-756. http://dx.doi.org/10.5424/sjar/2010083-1274

Hulse JH. 1991. Nature, composition and utilization of grain legumes. In: Uses of tropical Legumes: proceedings of a Consultants' Meeting, 27-30 March 1989, ICRISAT Centre. ICRISAT, Patancheru, A. P. 5502324, India. 11-27.

Ingold CT, Hudson HJ. 1993. The biology of fungi. Chapman and Hall, New York. http://dx.doi.org/10.1007/978-94-011-1496-7

Nair NG, Allen RN. 1993. Infection of grape flowers and berries by Botrytis cinerea as a function of time and temperature. Mycological Research, 97:1012-1014. http://dx.doi.org/10.1016/S0953-7562(09)80871-X

Pande Suresh, Sharma Mamta, Kishore G. Krishna, Shivram L, Naga Mangala U. 2010. Characterization of Botrytis cinerea isolates from chickpea: DNA polymorphisms, cultural, morphological and virulence characteristics. African Journal of Biotechnology, 9(46):7961-7967.

Pande S, Galloway, Gaur PM, Siddique KHM, Tripathi HS, Taylor P, MacLeod MWJ, Basadrai AK, Bakr MA, Joshi S, Kishore KG, Isenegger DA, Narayana J, Sharma M. 2006. Botrytis gray mold of chickpea: a review of biology, epidemiology and disease management. Australian J. Agril. Res., 57:1137-1150. http://dx.doi.org/10.1071/AR06120

Pande S, Singh G, Rao JN, Bakr MA, Chaurasia PCP, Joshi S, Johansen C, Singh SD, Kumar J, Rahman MM, Gowda CLL. 2002. Integrated management of botrytis gray mold of chickpea. Information Bulletin No. 61, ICRISAT, Andhra Pradesh, India.

Pandey BK. 1988. Studies on Botrytis gray mold of chickpea (Cicer arietinum L.).Ph.D thesis, Govind Ballabh Pant University of Agriculture and Technology, Pantnagar, Uttar Pradesh, India.

Phillips DJ, Margosan DA, Mackey BE. 1987. Size, number, and aggressiveness of Botrytis cinerea spores produced on media of varies glucose concentrations. Phytopathology, 77:1606-1608. http://dx.doi.org/10.1094/Phyto-77-1606

Rewal N, Grewal JS. 1989. Effect of temperature, light and relative humidity on conidial germination of three strains of Botrytis cinerea infecting chickpea. Indian Phytopathology, 42:79-83.

Shaw FJF, Ajrekar SL. 1915. The genus Rhizoctonia in India.Memories of the Department of Agriculture in IndiaBotanical Series.7:177.

Shirane N, Masuko M, Hayashi Y. 1989. Light microscopic observation of nuclei and mitotic chromosomes of Botrytis species. Phytopathology 79(7), 728-730. http://dx.doi.org/10.1094/Phyto-79-728 